\title{
A Brief Analysis of Subtitle Translation of Documentary Wild China from the Perspective of Eco-translatology*
}

\author{
Yang Zhou \\ School of Foreign Languages, Tianhe College of Guangdong Polytechnic Normal University, China \\ Rouqi Zhang \\ Sure Link Technology (Guangzhou) Co., Ltd., China
}

\begin{abstract}
Based on the principle of truth, the documentary exchanges knowledge and conveys emotions. The documentary Wild China has received strong attention from domestic and foreign audiences since its launch on National Geographic. However, due to the differences between Chinese and Western cultures, most Chinese viewers need subtitle translation to have a better understanding of this documentary. Unlike the subtitle translation of films and TV plays, the content of the documentary has strong professionalism and knowledge. Thus, documentary subtitle translation requirements are also higher than those of films and TV plays. Meanwhile, it is necessary to discuss the subtitle translation of documentaries. Ecological translation was first proposed by Professor Hu Gengshen. In the past ten years, many remarkable research results have been achieved. Taking ecological translation as the theoretical support, this paper chooses the subtitle translation of the documentary Wild China (CCTV) as the research object, and combines the theoretical discussion and the case analysis to focus on the translator's "adaptation" and "selection" in the linguistic, cultural and communicative dimensions, thus verifying the guiding significance of eco-translatology to the subtitle translation of the documentary and supplementing the theoretical research perspective of subtitle translation of the documentary.
\end{abstract}

Index Terms -Eco-translatology, documentary, subtitle translation, "adaptation" and "selection"

\section{INTRODUCTION}

Among many films and TV works, the documentary, as a special form of film and television, presents vivid images to the audience, which plays an important role in the cultural exchanges between China and foreign countries. Based on the principle of truth, the documentary conveys knowledge and emotions, and enjoys a special status in the audience's mind. It is an important channel for transmitting information and spreading culture. As China and the west have different languages, which contain different cultures, thoughts and language habits, most Chinese audiences have to resort to subtitle translation if they want to have a better understanding of the documentary content. After the documentary Wild China was released by CCTV9 channel in China, it was praised by domestic and foreign audiences. The reason lies in the fact that this documentary series is not only featured with unique themes and brilliant shooting pictures, but also featured with high-quality subtitle translation.

Subtitle translation is an interdisciplinary study, belonging to the category of audio-visual translation (AVT). In recent years, there have been more and more researches on subtitle translation in China, but there are few studies on subtitle translation of documentary films. Eco-translatology studies were first proposed by Professor Hu Gengshen at the Asian Translation Forum in 2001, which has been widely echoed by the translation circles. Since then, the academic research on eco-translatology has been continuously deepened and expanded, making a profound and critical interpretation of the theory, and the research results are very rich. And the translation of documentary subtitles under the guidance of ecological translation studies is undoubtedly a "new star" in this field. The theory developed on the basis of Darwin's theory of evolution "adaptation and selection" and "translator centeredness", which focuses on translators" subjectivity and responsibility in the process of translation. With the principle of "adaptation and selection", the theory tries to seek the ecological balance of translation and provides the subtitle translation of documentary with new scope. Ecological translation studies will undoubtedly bring more profound significance to the documentary subtitle translation strategy and evaluation.

Conducted from the perspective of Eco-translatology, this paper takes the subtitle translation text of documentary Wild China as an example, and it combines with case analysis from the perspective of multi-dimensional integration to discuss translators' adaptation and selection, and proposes translation strategies of documentaries. It can be found that

\footnotetext{
* Guangdong Educational Science Planning Program+Development of Translator's Competence from the Perspective of Eco-translatology: A Case Study of English Majors in Independent Colleges (2017GXJK252)
} 
translators try to integrate the linguistic, cultural and communicative dimensions and mainly adopt strategies to adapt to the target ecological environment. Translators adapt and select different dimensions in different translation processes to adapt to the original ecological environment and achieve the optimal translation effect. Through analysis of the documentary Wild China subtitle texts, the paper attempts to explore the translators' influence on translation activities and test the applicability of Eco-translatology in translation practice.

\section{An Overview of Documentary Films AND the Subtitle Translation}

With the further promotion of the strategy of "One Belt, One Road", the spreading of Chinese culture to the world is speeding up. Under the environment of frequent cultural exchanges and interactions between China and foreign countries, documentaries, as a cultural carrier, undertake the sacred mission of carry forward the long history and splendid treasures of Chinese civilization to foreign countries. Therefore, the quality of subtitle translation will affect the spread and the development of culture. In recent years, the subtitle translation of documentaries has attracted more and more attention from scholars at home and abroad, and relevant documentary subtitling translation studies in China have been increasing.

\section{A. The Development and Influence of Documentary Films}

Documentary is a kind of documentary film which records real life materials, shows real people and facts and renders them artistically. People and events recorded in documentaries are real. However, academia has not been able to give a specific definition of documentaries.

With the gradual development of documentary, scholars have also explained the definition of documentary from different angles. According to Dziga Vertov, a former Soviet director, documentaries show "life as it is", which means they can be made secretly or "life caught unawareness". While Bill Nichols believes that documentary definitions should be studied in many ways, such as text, participants, and traditional methods of recording, changes in the history of development and so on. Thus, there are many angles for defining a documentary, and the documentary itself is a wide-ranging visual expression. And the documentary forms and recording methods will also change according to the different purposes.

This paper taking the natural documentary Wild China, aims to analyze and discuss the influence of the translation of Chinese cultural documentary on Chinese culture "going out". With the in-depth implementation of "One Belt, One Road" project, it is imperative for Chinese culture to spread globally. Works in the form of art, films and TV plays are the output carriers of cultural communications, among which documentaries play an important role.

\section{B. Current Studies on Subtitle Translation}

Subtitle translation is a multimedia translation, which is also a category of audiovisual translation (AVT). Subtitle translation is one of the most common models in the field of audio-visual translation. Due to the rapid development of films in Europe, the research on subtitle translation in Europe is more advanced than in China. Franco points out that documentary translation is a special practice. Therefore, to some extent, the use of "exoticism" in subtitle translation can be welcomed by the audience of documentary export.

In 1993, after the establishment of China Documentary Research Center, domestic scholars focus on the development of Chinese documentary. However, there are still little research on the translation of documentary subtitles. Most scholars have conducted a lot of research on film and television translation from the western perspectives of Relevance Theory, Skopos Theory, Descriptive Translation Theory and Multi-system Perspective. Cheng Wei considers that the subtitle translation of documentaries should adjust register according to different contexts in order to enhance the readability of subtitles.

\section{THEORETICAL FRAMEWORK}

It can be seen that eco-translatology including "ecology" and "translatology" is a multi-disciplinary and comprehensive discipline, and its intersection is eco-environment and translation context. That is to say, Eco-translatology originated from translation studies in the light of ecology.

In 2001, ecological translation studies were on the stage of international translation theory research, demonstrating that translation studies can be organically integrated with the natural sciences. Professor Hu Gengshen's lecture "From the Darwinian Principle of Adaptation and Selection to Translation Studies" provide a new perspective for interdisciplinary translation research.

\section{A. The Origin of the Eco-translatology Theory}

Since its birth in 2001, ecology has attracted considerable attention and has been making a comprehensive development since 2009. In the 1970s, the concept of "Deep Ecology" was proposed by the philosopher Arne Naess, who applied ecology into the concept of philosophy and ethics. After that, the American ecological philosopher David Griffin put forward the concept of "Eco-existence" on the basis of philosophical research, leading scholars to study translation activities from the perspective of "ecological integrity of translation".

Based on previous translation studies, some scholars have already done some research from the perspective of 
ecology, and the terms "ecology", "environment", "survival" and "adaptation" can be found in previous translation studies.

\section{B. Main Concepts of Eco-Translatology Theory}

The development of ecological translation in China has been influenced by the Chinese civilization. "Life experience can be regarded as a mainstream of Chinese cultural thought, which contains the understanding of ecology and reflects the wisdom of traditional Chinese culture. " (Hu, 2004, p.62) These wisdom include "the unity of man and nature", "Taoistic Thought Emulates Nature", "the golden man" philosophy and "people-oriented". Guided by Darwin's "adaptation and selection", this theory discusses the interaction, characteristics and patterns of translator's adaptation and selection.

1. Eco-environment of translation

In 2001, Hu Gengshen proposed the concept of "translational eco-environment" to introduce the translation adaptation options. Different from the terms such as "context", "macro context and micro context" or "cultural context", the concept of "translational eco-environment" is used for accuracy in translation, because it contains the original language system and target language system.

"Ecological environment" is the total environment constituted by all ecological relationships, that is, the sum of all external factors that affect or restrict the survival or development of human beings and other organisms. "Translation Ecology refers to the state of interrelation and restriction between the different subjects of translation and the factors of the external environment." (Hu, 2004, p.81-82)

2. Translator-centeredness

"With the triangle of 'source text-translator-target text', the translator is the 'center' of communication between the source text and the target text." (Hu, 2004, p.29-35)

Different from the traditional structuralist "translator-centered" theory, the translator is the conscious leader in the process of translation. In addition, "translator-centered" will not deprive of the importance of "text". "Translator-centered" emphasizes that improving the quality of text translation depends on the translator's high-level translation skills. In other words, the translator is responsible for coordinating and balancing everything involved in the translation process, such as the translational eco-environment, the text ecology and public ecology.

3. Translator's adaptation and selection in process of translation

Eco-translatology, as the unique symbol of Hu Gengshen's translation thinking, leads the dynamic common association among "what's translation" "who-translate" "how-to-translate" and "why-translate". And in the answer to "what's translation", Professor Hu give an importance view of "translation is adaption/selection". (Hu, 2004, p.204 )

In Eco-translatology, "adaptation and selection" can be regarded as the translator's instinct and the essence of translation. "The process of translating is divided into two stages: the translational eco-environment selects the translator, and the translator selects the form of the target text." (Hu, 2004, p.222) In short, the translator should accept the restrictions of the translational eco-environment, or the translator should choose an appropriate translation to adapt to the translational eco-environment of the specific translation task, thus his translation will win the opportunity to become successful.

\section{The Applicability of Eco-translatology in Documentary Subtitle Translation}

Based on the theory of eco-translatology, in the practice of documentary subtitle translation, the translator must first analyze the translation eco-environment of the source text to make right decisions on the translation strategies so as to "adapt" to the original ecological environment. Since subtitle translation is limited by screen space and playback time, the translator has to express the source language information and cultural factors in a concise and easy-to-understand language in the process of translation to convey the linguistic information and cultural connotations contained in the documentary to the target audience.

Documentary subtitle translation is highly professional and knowledgeable whose "translational eco-environment" is different from that of other films and TV series. Therefore, it has guiding significance for the research on analyzing the English documentaries subtitle translation from the perspective of eco-translatology.

\section{ANalysis of Subtitle Translation of WiLd China in Light of ECo-TRANSLATOlogy Theory}

This paper will study the subtitle translation that is released on CCTV. Nowadays, researches on subtitle translation of Wild China have been studied from perspectives of linguistics, aesthetics, culture, communication and so on. However, as for the subtitle translation of Wild China from the perspective of Eco-translatology, there are several paper and articles can be found from CNKI.

\section{A. A Brief Introduction to Wild China}

The television program Wild China is a nature documentary series in China, which is the first co-produced TV program by BBC Natural History Unit and CCTV. Wild China shows the wildlife and natural landscape of China and is also a good learning material for translation. The language is vivid and fluent, which is highly consistent with content.

1. The influence and significance of Wild China 
After its debut on BBC around the world in 2008, the BBC version of Wild China was translated into different languages and various subtitles by fansub (fan-subtitled) groups and became popular online. And then in January 2011, it was translated and broadcast on the CCTV recording channel, which was widely popular among the Chinese audience.

"The cultural value of BBC Natural History Unit is to photograph wildlife, discover wildlife, introduce wildlife knowledge to the world and guide us in protecting wildlife to the whole world." (Feng, 2013, p. 22) The CCTV version of Wild China was not translated literally in accordance with the English subtitles of the BBC version. Instead, the translators not only take the Chinese audience's demand knowledge and cultural background into account carefully, conforming to the expression of Chinese habit, but also achieve the expected effect of subtitle translation of the documentary.

2. Current studies on the subtitle translation of Wild China

Recently, Zheng Ya analyzes the subtitle translation of Wild China from the perspective of linguistic, cultural and communicative dimensions of eco-translatology by fully considering the differences between Chinese and English in linguistic dimension, delivering the cultural connotations in terms of cultural dimension, and abandoning verbatim translation to emphasize whether the function of communication is achieved. "The perspective of eco-translatology can provide new insights into the study of subtitle translation of Wild China." (Zheng, 2015, p. 55)

In light of these considerations, this paper attempts to use CCTV translations of Wild China as materials to focus on the translator's "adaptation" and "selection" in the linguistic, cultural and communicative dimensions, thus verifying the guiding significance of eco-translatology to the subtitle translation of the documentary. It is hoped that the paper can be used as a pilot to explore differences in subtitle translations between Chinese and English.

\section{B. Eco-environments of Subtitle Translation of Wild China}

According to Professor Hu Gengshen's definition of the "translational eco-environment": "The worlds of the source text and the source language/target language, comprising the linguistic, communicative, cultural and social aspects of translating, as well as the author, the client, and the reader." (Hu, 2004, p.90)

From a macro perspective, the translational eco-environment is related to the macro environment of the economy, politics and culture. From a micro perspective, the eco-environment refers to the overall detailed translations of source language, source text and target text.

1. Subjective environment

The prominent issue in the translation activities of Wild China is about copyright, which the translation initiator should take into account. The initiator is the starting point of a specific translation activity and he decides the communicative purpose in the process of translational action. In order to promote the Chinese version of Wild China, the initiator will be inevitably in search of the publishers like some famous online video sites. To sum up, the success of translation depends on the translator's adaptation to translational environment as well as on the harmonious coexistence among the translation subjects.

2. Objective environment

So far, economy has always been the top primary factor in the activities, and translation activities are no exception. Economic motivation is the definitive factor to promote the production of Wild China.

Secondly, language is a mirror of a culture and translation is the cultural exchange between source language and target language. There remain some differences between western culture and eastern culture on the linguistic expressions and thinking ways. In addition, the last two decades have witnessed the China's rapid economic development, growing national strength and rising international status.

\section{Three Dimensional Transformations in the Process of Adaptation and Selection}

In view of the main descriptions of the two translational ecologies in linguistic, communicative and cultural ecology, the degree of mufti-dimensional transformations is mainly reflected in linguistic, cultural and communicative dimensional transformations.

1. Linguistic-dimensional transformation

In the subtitle translation of Wild China, the linguistic selective can be regarded from two aspects: syntactic level and lexical level owing to the linguistic differences between Chinese and English.

With regard to syntactic level, English language is logical and cohesive as well as with the clear structures of subjects and predicates, hence conjunctions, prepositions and pronouns are used frequently. Chinese people, by contrast, are accustomed to paying more attention to things on the overall rather than the details. "Passive voice is occupied in English articles. In some special literary forms, such as technical works, newspapers and magazines and so on, passive habits have almost dominated the entire text." (Lian, 2010, p.118)

Here, the linguistic data and the target texts come from the CCTV version of documentary Wild China.

Source Text 1: This may look like a slaughter, but as each heron can swallow only one frog at a time, the vast majority will escape to croak another day.

Target Text 1: 捕猎的场面很快就结束了, 每只池鹭一次只能吞下一只青蛙, 大多数青蛙还是逃脱了, 第二天 他们依旧在水田中鸣叫。

Source Text 2: As the stars rise, the witch begins to cast her spell. 
Target Text 2: 夜幕降临繁星满天, 从林女巫开始释放她的魔力。

Source Text 3: Yunnan's rice terraces are among the oldest human structures in China, still ploughed, as they always have been, by domesticated water buffaloes, whose ancestors originated in these very valleys.

Target Text3: 云南的梯田是中国最古老的人造梯田之一, 我们的祖先也许没有想到, 他们的子孙后代, 至今 还在使用这种传统的耕作方式。

In the above four examples, the same conjunction "as" can be found in the source text. We can figure out that there are three meanings when "as" is used as a conjunction. In the the source text 1, "as" is often translated into “因为, 由 于" in Chinese in the middle of the sentence, which is used to mean "because". In the source text 2, "as" means that "if something happens as something else happens, it happens at the same time", which we often use “随着, 当...的时候” in Chinese. In source text 3, “as" can be translated into “正如, 就像” in Chinese which means “if" when describing something may happen in the same way as something else.

Compared with the source texts, the CCTV version leave out the conjunctions in Chinese and these words like Chinese “因为, 由于” “随着, 同时” “正如, 就像” can not be found in the target texts. In other words, the translation of CCTV version conforms to the linguistic habits of Chinese and reflects their ways of thinking. Thus, the Chinese audience can better understand the translated versions very well even if these sentences are given a quick-look.

Source Text 4: Now, for the first time ever, we can explore the whole of this great country, meet some of the surprising and exotic creatures that live here and consider the relationship of the people and wildlife of China to the remarkable landscaping which they live.

Target Text 4: 深入探索这片伟大的土地, 接触栖息于此的珍奇生物, 目睹中国这片神奇土地上人与野生世界 的羁绊。

The above example consists of several long sentences. However, the target translations contain three or more short clauses. In the source text 4, "that live here" and "which they live" act as an attributive clause in the original sentences, which the translator translates into two independent clauses in Chinese. Meanwhile, there are three predicates in this long sentence: "explore" "meet" and "consider". And it is translated into three short Chinese units, which indicates English language is logical and cohesive as well as with the clear structures of subjects and predicates, that Chinese language emphasizes parataxis.

Source Text 5: Established in 2001, it's the first of its kind. Here owls are given medical attention by Sun quantum and his team. The birds are even exercised to help their rehabilitation. Once deemed fit and healthy, the owls are taken to the hills at the edge of Beijing.

Target Text 5: 这家中心成立于 2001 年, 是国内第一家猛禽救助中心。在这里, 猫头鹰得到了全面的救治, 医 生们还会帮助它们做快康复训练，当医生确认猫头鹰身体已经痊愈，他们就会被送往京郊的山上放飞。

In the target text of Chinese translation, “医生” is mentioned and is substituted in the active voice except the second and the last one sentence. Here, the translation “医生们还会帮助它们做快康复训练, 当医生确认猫头鹰身体已经痊 愈” maintains conciseness and coherence from the syntactical level. Nevertheless, the use of passive and active voice in the translation activities should be selected under the actual circumstances.

With regard to the lexical level, translators focus on the usage of vocabulary, figure of speech and connotation of words in the process of translation. Language is a symbolic system, and its signifier as well as the signified is unique in different languages. As Chinese and English come from different language systems and cultures, the meaning of word is translators adopt selective transformations in subtitle translation of Wild China from the lexical level.

Source Text 6: This man-made landscape is one of the most amazing engineering feast of the pre-industrial China. It seems as if every square inch of land has been pressed into cultivation.

Target Text 6: 这个人造地形是中国工业化以前的鬼斧神工，每一寸土地似乎都可以被开唇做耕种用。

Source Text 7: The forests that lie south of the Black Dragon River are bound up in snow for more than half the year. It is deathly silent.

Target Text 7: 黑龙江以南的树林, 一年过半时间冰雪盖掩, 万籁俱寂。

In the example 6, the original subtitles "one of the most amazing engineering feast of the pre-industrial China" is translated into “鬼斧神工” which presents pieces of beautiful paintings from the film to Chinese audience. The literal translation “一项最令人惊讶的工程” surely is acceptable by the target audience but failed to adapt to the target linguistic environment.

In the source text 7, it is trying to show the picture that forests covered in white snow are peacefully beautiful. The target text “万籁俱寂” is totally different from “那是全然的死寂”, the former one describes the silence of the winter forests in the south of the Black Dragon River in an objective way, and the latter one could evoke arouse a terrible sense of silence like death. Therefore, the four-word expression “万策俱寂” is more preferable.

In conclusion, as noted above, the main characteristic of the translation of example 6 and example 7 is the use of four-character terms, which plays an important role in the process of E-C documentary subtitling. From the lexical level, the selection of words indicates the traditional Chinese language features like four-character terms in accordance with the language conventions of Chinese people.

2. Cultural-dimensional transformation 
Due to the difference regarding nature and content of the source and target culture, in order to avoid misinterpreting the source text from the angle of the target cultures, the translator is required not only to pay attention to the transformation in linguistic dimension, but also to adapt to the cultural system that the language belongs to and convey its cultural connotation in the translation process.

Here, translator's cultural adaptive transformations can be mirrored in the examples of the subtitle translation of Wild China.

Source Text 8: Several world religions believe in a mythical mountain. That's equivalent to the Garden of Eden. Its peak has four faces, aligned to the points of the compass, and from its summit four rivers are said to flow to the four quarters of the world. Thanks to its life-giving waters, this mountain is known as the axis of the world.

Target Text 8: 多个宗教奉一座神山极乐世界, 传说神山峰顶有四壁, 对应东西南北四方, 顶峰流出四河, 流 向人间四方，大河河水灌溉生灵，于是人人奉神山为“世界中心”。

In the source text 8, “The Garden of Eden” is not familiar to all Chinese audience. So the literal translation “旧约的 伊甸园” is not proper, yet the translation of target text “极乐世界”, which helps Chinese audience better understand why "mythical mountain" is a dream place for many different religious believers. Besides, "the points of the compass" is translated into “东西南北方”, because it corresponds to “人间四方” originated from the text “the four quarters of the world".

Source Text 9: Wild China (The title of this documentary.)

Target Text 9: 《美丽中国》

"Wild China" is the English title of BBC's natural documentary film. From the concepts of Chinese traditional culture, the word “野” means "rude or impolite", which sounds like an insult to the country. Therefore, the Chinese audience will feel uncomfortable if the title is translated into “野性中国” or “狂野中国”. The Chinese translation “美 丽中国” of CCTV version could be the most suitable because this documentary is aimed to introduce the natural beauty of China and protect the ecological environment in China.

Based on the examples above, it is obvious that the translator selects adaptive transformations to both the original text and the target text when confronted with culture-loaded words. We can see that CCTV version of Wild China has achieved higher degree of holistic adaptation and selection in the cultural dimension.

3. Communicative-dimensional transformation

In addition to linguistic and cultural transformations, ecological translation also includes communicative transformation which is also essential in the process of translation.

In the process of translation, the communicative intention needs to be seized by the translator to transmit the communicative information accurately. There are some subtitle translations of Wild China involving communicative characteristics of language.

Source Text 10: Dragon eggs are greatly prized.

Target Text 10: 龙蛋被认为价值连城。

The original text 10, “prize” is translated into “价值连城”, which is more successful and creative. If translated literally, the "prize" will be lost to Chinese audience. The meaning of the word "prize" is mostly "evaluation" or "cherish" and "appreciation" Thus, it is appropriate to use it to express "the value for Dragon eggs". In the subtitle translation of documentaries, the translation of “价值连城” is concise, intuitive and readable, in the meantime, the language is highly communicative.

Source Text 11: Crowning the canopy, rhododendrons, up to 30 metres high.

Target Text 11: 万绿从中点点红。

In the original sentence, the word “crown” has the common Chinese meaning of “加冕”, which is obviously inappropriate to translate literally in the sentence. Based on the film display. the picture presented in the video is a brightly blooming azalea in the mountains and plains, red and green.

It can be seen that the translation based on the scene of the picture to describe the translation is translated directly into “万绿从中点点红”. The translator selects its most appropriate expression to carry out the meaning of the content and meaning of the picture. In this way, not only can the subtitles be consistent with the video picture, but also the audience accept the way to communicate with the film.

Source Text 12: Like so much monkey business, what starts off as a bit of playful rough-and-tumble.

Target Text 12: 像多数的胡闹, 开始是一点点的打闹。

According to the picture presented by the video, the original sentence shows that the monkeys are playing. But the word "business" is easy to misunderstand. The word "business" in the dictionary originally means "commercial thing". If it is translated into "monkey doing business", this statement will lead to the misleading communication between Chinese and English. As the picture shows: the little monkey is playing, so the original translation is translated into “打 闹”. Thus, the meaning of this translation is more accurate, and the audience will not be misunderstood in the process of watching.

To sum up, the translator modifies some improper information to eliminate misunderstanding and ensure the message equivalence. Moreover, the translator selects adaptive transformations between the source text and target translational 
eco-environment to deliver the communicative intention. Therefore, the CCTV version of Wild China has high degree of holistic adaptation and selection in terms of communicative dimension.

\section{Research Findings}

Based on the above analysis, it can be seen that the high quality translations depend on the high degree of multi-dimensional transformations. Transformation is dynamic and interrelated because the translating is also dynamic and developing with regard to the three dimensions. On the analysis of the comparison of the Chinese version of Wild China, we can conclude that the CCTV version has high degree of holistic adaptation and selection in three dimensional transformations.

1. Translator's subjectivity and responsibility

The final presented documentary of Wild China takes on many works in which translator is an indispensable part for the of subtitle translation. Meanwhile, the translator at the same time, the translator is also responsible for coordinating the relationship between the source text and the target text. Finally, considering the factors involved in balancing, translators need to make adaption and decision in the final target text that should conform to the principle of ecological balance.

The translator's competence of translation quality can hardly be measured due to the shortage of specific information about the translation tea. However, from the above analysis, we can draw a conclusion that this is a qualified translation team which engaged in translating the Chinese version of Wild China, because the transformation in linguistic dimension, cultural dimension as well as communicative dimension is successfully achieved by the translators here.

2. Readers' feedback

The potential readers of the translated subtitle as well as the audience of Wild China are those who may live far away from China but are still deeply eager to learn more about the culture and enjoy the natural landscapes of China. According to the data presented on the Internet, the play number of Wild China has been continuing to grow after it is premiered. These figures show that the subtitle translation of the Chinese version of Wild China has gained popularity among the public.

3. Enlightenment for further research

There are still some limitations to this study. First of all, it is a relative new theory both at home and abroad, so the materials available for reference are limited. Secondly, in the process of translation evaluation, there is no discussion of factors on translator's quality for lack of material. Thirdly, the case study mainly focuses on the natural history documentary Wild China. Therefore, more examples from different types could be used for further research to validates the explanatory power of Eco-translatology.

\section{CONCLUSION}

In summary, this paper analyzes the subtitle translation of the documentary of Wild China from the perspective of Eco-translatology, which emphasizes the translation strategies of adapting the target text ecological environment, as well as the integration of the translation in the translation process.

The natural history documentary Wild China has impressed people not only with its content and beautiful pictures, but also the amazing subtitle translation in this film. From the perspective of ecological translation theory, the subtitle translation of Wild China realizes the three-dimensional transformations - linguistic, cultural and communicative transformations. The wonderful content is shocked by instant subtitles, thus maximizing the cultural value and art of the documentary. However, these three dimensions are not independent in the process of translation. In short, the translator should make the best adaptive selection in the translation process to realize the best three-dimensional transformations in the limited time and space, and to provide the most effective and expressive translation for the audience when subtitle translation is performed.

In China, there is relatively less study on the documentary subtitle translation. Hopefully, the documentary truly becomes a bridge between cultural communication and language communication between countries through helping the audiences of different countries cross the language, culture and communication barriers to better understand and appreciate different types of documentaries. So far, there is no complete system of translation theory based on film and television plays at home and abroad. The translation of documentary subtitles from the perspective of ecological translation theory aims to attract more experts and scholars to study and explore the theory of and the documentary subtitles translation, so as to further improve the quality of English documentary subtitle translation.

\section{REFERENCES}

[1] Feng, Xin. (2013). Cultural dialogue achieved in the Sino-foreign cooperated documentary film Wild China. Journal of Lanzhou University (Social Science), 1, 27-32.

[2] Hu, Gengshen. (2003). Translation as adaptation and selection. Perspectives: Studies in Translatology, 4, $283-291$.

[3] Hu, Gengshen. (2004). An approach to translation as adaptation and selection. Wuhan: Hubei Education Press.

[4] Hu, Gengshen. (2004). Translator-centredness. Perspectives: Studies in Translatology, 2, 106-117.

[5] $\mathrm{Hu}$, Gengshen. (2006). Exemplification of translation principles and methods of adaptation and selection. Foreign Languages and Their Teaching, 3, 49-53. 
[6] Katan, David. (1999). Translating cultures. Manchester: St. Jerome Publishing.

[7] Lefevere, A. (1992). Translation, rewriting, and the manipulation of literary fame. London/New York: Routeledge.

[8] Lian, Shuneng. (2010). Contrastive studies of English and Chinese. Beijing: Higher Education Press.

[9] Newmark, P. (1991). About translation. Philadelphia/Adelaide: Multilingual Matters Ltd,.

[10] Nida, E. A. (1993). Language, culture, and translating. Shanghai: Shanghai Foreign Language Education Press.

[11] Snell-Hornby, M. (2001). Translation studies: an integrated approach. Shanghai: Shanghai Foreign Language Press.

[12] Venuti, Lawrence (1995). The translator's invisibility. London \& New York: Routledge.

[13] Wilss, W. (1996). Knowledge and skills in translator behavior. Amsterdam/Philadelphia: John Benjamins Publishing Company.

[14] Zheng, Ya. (2015). Subtitling translation of Wild China: an Eco-tranlatology pespective. Journal of Hubei University of Arts and Science, 12, 55-58.

Yang Zhou was born in Hunan, China in 1984. She received her Master's Degree in Linguistics Applied and Linguistics Abroad from Sun Yat-sen University in 2009.

She is currently a lecturer in the School of Foreign Languages, Tianhe College of Guangdong Polytechnic Normal University, Guangzhou, China. Her research focus is on Translation Practice and Theory.

Ms. Zhou has won a lot of prizes in teaching.

Rouqi Zhang was born in Guangdong, China in 1996. She received her Bachelor's Degree in English from Tianhe College of Guangdong Polytechnic Normal University.

She is currently an executive assistant in an Internet company. 